\title{
Harran Ovası Koșullarında Yetiștirilen Mısır Bitkisinde (Zea mays L. indentata) Farklı Ekim Sıklıklarının Silaj Verimi ve Kalitesi Üzerine Etkisi
}

\author{
Timuçin TAȘ ${ }^{1},{ }^{*}$ Ayșe Gülgün ÖKTEM ${ }^{2}$, Abdullah ÖKTEM², Abdulkadir SÜRÜCÜ ${ }^{3}$ \\ ${ }^{1}$ GAP Tarımsal Araștırma Enstitüsü Müdürlüğü, Șanlıurfa \\ ${ }^{2}$ Harran Üniversitesi Ziraat Fakültesi, Tarla Bitkileri Bölümü, Sanlıurfa \\ ${ }^{3}$ Harran Üniversitesi Ziraat Fakültesi, Toprak Bilimi ve Bitki Besleme Bölümü, Șanlıurfa \\ *Sorumlu yazar e-posta (Corresponding author e-mail): aoktem@harran.edu.tr
}

\begin{abstract}
Öz
Bu araștırma ile farklı ekim sıklı̆ı uygulamalarının, silajık mısıın yeșil ot verimi ile silajılık yem kalite özelliklerine etkisini belirlemek amaçlanmıștır. Araștırma 2010, 2011 ve 2012 yıllarında üç yıl süre ile Harran ovası ikinci ürün koșullarında yürütülmüștür. Deneme tesadüf blokları deneme deseninde üç tekrarlamalı olarak kurulmuștur. Bitkisel materyal olarak Samada-07 silajık mısır çeșidi kullanılmıștır. Araștırmada beș farklı ekim sıklığı kullanılmıștır. Ekim sıklıkları; 10 cm (14285 bitki/da), 14 cm (10204 bitki/da), $18 \mathrm{~cm}(7937$ bitki/da), $22 \mathrm{~cm}$ (6493 bitki/da) ve $26 \mathrm{~cm}$ (5494 bitki/da) șeklinde uygulanmıștır. Araștırmada yeșil ot verimi, NDF (Nötral Deterjan Lif), ADF (Asit Deterjan Lif), ADL (Asit Deterjan Lignin), ham selüloz ve kül miktarları gibi özellikler incelenmiștir. Elde edilen araștırma sonuçlarına göre; incelenen özellikler bakımından ekim sıklıkları arasında istatistiki önemde farklılık belirlenmiștir. En yüksek silaj verimi (6884 kg/da) 14286 bitki/ da ekim sıklığında (10 cm sıra üzeri) belirlenmiștir. Bitki sıklığı artııç̧a yeșil ot verimi, NDF, ADF, ADL, ham selüloz ve kül miktarları değerleri artmıș, ancak kalitede azalma gözlenmiștir.
\end{abstract}

Anahtar Kelimeler: Mısır, ekim sıklı̆ı, NDF, ADF, ADL

\section{The Effect of Different Plant Density on Silage Yield and Quality of Corn Plant (Zea mays L. indentata) under Harran Plain Conditions}

\section{Abstract}

This research was conducted to determine the effects of different sowing densities on green grass yield and forage quality characteristics of silage maize. The study was conducted in Sanliurfa during the second crop corn growing season of 2010, 2011 and 2012. The study was conducted in randomized block design with three replications. Samada 07 silage corn variety was used as plant material. Five sowing densities were used in the study. They were: $10 \mathrm{~cm}$ (14285 plants/da), $14 \mathrm{~cm}$ (10204 plants/da), $18 \mathrm{~cm}$ (7937 plants/ da), $22 \mathrm{~cm}$ (6493 plants/da) and $26 \mathrm{~cm}$ (5494 plants/da). In the study, green grass yield, NDF (Neutral Detergent Fiber, ADF (Acid Detergent Fiber), ADL (Acid Detergent Lignin), crude cellulose, and ash contents were investigated. According to results of the research; plant densities were statistically significant for the examined characteristics. The highest green grass yield $(6884 \mathrm{~kg} / \mathrm{da})$ was found at $14286 \mathrm{plants} / \mathrm{da}$ planting density (10 cm intra row spaces). Silage yield, NDF, ADF, ADL, crude cellulose and ash contents increased with increasing plant densities but the quality decreased.

Keywords: Corn, plant density, NDF, ADF, ADL

\section{Giriș} ürkiye'de mısır, tane olarak yem ve silaj olarak hayvan beslenmesinde kullanılmaktadır. Mısır silajı büyükbaș hayvan besiciliğinde yaygın olarak kullanılan en ekonomik kaba yemdir. Ülkemizde hayvancılığın gelișimine paralel olarak silaj mısır ekim alanları ve üretim miktarı 20042016 yılları arasında artmıștır. Türkiye'de

413.827 ha alanda silajlık mısır ekilmiș, 20.139.033 ton üretim gerçekleșmiș, 4868 kg/ da verim elde edilmiștir (Anonim, 2017). GAP projesiyle beraber sulamaya açılan üretim alanlarının artmasıyla silaj mısır üretim miktarı artmıștır. Güneydoğu Anadolu Bölgesi'nde silaj mısır 185.223 da alanda ekilmiș, 757.882 ton üretilmiș ve 4092 kg/da verim verim edilmiștir. 
Araștırmanın yürütüldüğg̈ Șanlıurfa ilinde ise 79.154 da alanda silajlık mısır ekilmiș, 349.944 ton üretim yapılmıș, $4421 \mathrm{~kg} / \mathrm{da}$ verim elde edilmiștir (Anonim, 2017). Güneydoğu Anadolu Bölgesinin silajlık mısır üretiminin yaklașık yarısı Șanlıurfa'da üretilmektedir.

Șanlıurfa'da yüksek oranda üretim yapılmasının nedenleri; GAP projesiyle beraber birçok ovanın sulamaya açılması, bölgenin ikinci ürün koșullarına uygun olması ve silajlık mısırın desteklenmesi șeklinde sıralanabilir.

Silaj mısırın performansını etkileyen faktörlerin; çeșit seçimi, bitki yoğunluğu, gübreleme ve hasat zamanı olduğu bildirilmiștir (Jeschke et al., 2010). Dekarda uygun ekim sıklığı ile bitkilerin topraktaki su, besin maddeleri ve ışık enerjisinden en etkin șekilde faydalanması sağlanmaktadır. Bu sayede hem verimi hem de kaliteyi arttırma imkânı bulunmaktadır.

Dünyada ve ülkemizde geçmiș yıllarda silajlık mısırın birim alan verimi öncelikli sıradayken, son yıllarda verim yanında yem kalite değerleri de ön plana çıkmıștır. Bitki hücre duvarları doğadaki karbonhidrat kaynağıdır ve geviș getiren hayvanlar için birincil enerji kaynağıdır. Mısır bitkisi hücre duvarları çoğunlukla polisakkaritler, selüloz, hemiselüloz ve oldukça karmașık bir polimer ligninden olușur (Lorenz, 2009). Mısırın lif yüzdesi ve kaba lifin bileșenleri (ADF, NDF ve $A D L)$ kuru madde sindirilebilirliği ile yakından ilișkilidir (Kim et al., 2001).

Kaba yem üretimi için mısırda bitki sıkığını azaltmanın uygun olmadığı, bu nedenle sıra üzeri mesafesinin dar tutulmasının mısır yeșil ot verimini arttırdığı, yeșil ot veriminin 51918099 kg/da arasında değiștiği belirtilmiștir (Bilgen ve ark., 1996). Doğan ve ark. (1997), bitki yoğunluğu arttıkça mısır bitkisinin yeșil ot verimi ile koçan sayısının arttığını, yüksek yeșil ot verimi için en uygun bitki yoğunluğunun $11.834 \mathrm{bitki} / \mathrm{da}$ olduğunu bildirmișlerdir. Soto et al., (2002), silajık mısırda dört farklı bitki yoğunluğunu $(7.000,9.000,11.000$ ve $13.000 \mathrm{bitki} / \mathrm{da}$ ) incelemișlerdir. En yüksek yeșil ot veriminin $(2960 \mathrm{~kg} / \mathrm{da})$ en yüksek bitki sıklığından alındığını bildirmișlerdir.

Hashemi et al. (2005), mısır bitkisinde yeșil ot verimi ile bitki sıklığı arasında kuadrik ilișki olduğunu ve maksimum verime $9000 \mathrm{bitki} / \mathrm{da}$ ve 12.000 bitki/da yoğunluklarında ulașıldığını bildirmișlerdir.

Öktem ve Öktem (2005), Harran Ovası koșullarında yaptıkları bir çalıșmada üç mısır çeșidinde dört farklı ekim sıklığını (6000, 7000, 9000 ve 10.000 bitki/da) denemișlerdir. Araștırmada, en yüksek yeșil ot verimi 9000 bitki/da sıklı̆ı̆nda, en düșük değer ise 6000 bitki/da sıklığında tespit edilmiștir. Araștıııcılar, bitki sıklığı azaldıkça yeșil ot verimi, kuru madde oranı ve kuru madde verimi, yaprak oranı ve sap oranının azaldığını belirtmișlerdir.

\section{Materyal ve Yöntem}

$\mathrm{Bu}$ çalıșma Harran Ovası koșullarında 2010, 2011 ve 2012 yıllarında üç yıl süre ile yürütülmüștür. Araștırmanın yürütüldüğü toprak kırmızı-kahverengi toprak grubu olup, profilleri killi tekstürlüdür. Profil çok kireçli ve KDK yüksektir. Organik madde yüzeyden așağılara doğru azalmakta, \%0,9-0,3 arasında değișmektedir. Çalıșmada bitkisel materyal olarak Samada-07 melez at diși mısır çeșidi kullanılmıștır. Deneme alanı buğday hasadından sonra pullukla sürülmüș, ardından goble disk ve diskaro geçirilerek kesekler parçalanmıș ve tapan çekilerek düzlenmiștir. Ekimden önce yapılan toprak tahlilindeki, $\mathrm{N}$ ve $\mathrm{P}_{2} \mathrm{O}_{5}$ miktarları dikkate alınarak bitkinin vejetatif dönemi boyunca saf $\mathrm{N}$ miktarı $30 \mathrm{~kg} /$ da, $\mathrm{P}_{2} \mathrm{O}_{5}$ miktarı $8 \mathrm{~kg} / \mathrm{da}$ 'ya tamamlanmıștır (Öktem, 2005).

Deneme tesadüf blokları deneme deseninde üç tekrarlamalı olarak kurulmuștur. Araștırmada beș farklı ekim sıklığı (14.285 bitki/da, 10.204 bitki/da, 7937 bitki/da, 6493 bitki/da ve 5494 bitki/da) kullanılmıștır. Ekim sıklıkları sıra üzeri mesafeleri daraltmak suretiyle elde edilmiș olup, $10 \mathrm{~cm}$ sıra üzeri mesafe ile 14.285 bitki/ da, $14 \mathrm{~cm}$ ile $10.204 \mathrm{bitki} / \mathrm{da}, 18 \mathrm{~cm}$ ile 7937 bitki/da, $22 \mathrm{~cm}$ ile $6493 \mathrm{bitki} / \mathrm{da}$ ve $26 \mathrm{~cm}$ ile 5494 bitki/da ekim sıklı̆ı elde edilmiștir. Her parsel 5 metre uzunluğunda dört sıradan meydana gelmiș olup sıra arası mesafeler $70 \mathrm{~cm}$, ekim derinliği ise $5-6 \mathrm{~cm}$ olarak ayarlanmıștır. Ekimden sonra yağmurlama sistemiyle tav suyu verilmiștir.

Çıkıștan sonra tekleme yapılarak parsellerde planlanan bitki sıklığı sağlanmıștır. 
Çizelge 1. 2010, 2011 ve 2012 yıllarına ait bazı iklim değerleri

Table 1. Some climate values for the years 2010, 2011 and 2012

\begin{tabular}{ccccccccccccc}
\hline \multirow{2}{*}{ Aylar } & \multicolumn{3}{c}{ En yüksek Sıc. $\left({ }^{\circ} \mathrm{C}\right)$} & \multicolumn{3}{c}{ Ortalama Sıc. $\left({ }^{\circ} \mathrm{C}\right)$} & \multicolumn{3}{c}{ Toplam Yağıș $(\mathrm{mm})$} & \multicolumn{3}{c}{ Ort. Nispi nem $(\%)$} \\
\cline { 2 - 14 } & 2010 & 2011 & 2012 & 2010 & 2011 & 2012 & 2010 & 2011 & 2012 & 2010 & 2011 & 2012 \\
\hline Haziran & 42.2 & 38.9 & 42.2 & 29.4 & 28.3 & 30.6 & 0.5 & 4.6 & 5.8 & 31.2 & 30.3 & 21.2 \\
Temmuz & 45.2 & 44.5 & 44.2 & 34.0 & 33.0 & 33.3 & 0.0 & 0.8 & 0.2 & 26.7 & 24.0 & 18.8 \\
Ağustos & 43.6 & 42.2 & 42.1 & 33.7 & 31.9 & 32.3 & 0.0 & 0.0 & 0.2 & 21.5 & 27.0 & 29.0 \\
Eylül & 40.0 & 39.1 & 39.9 & 28.5 & 27.5 & 28.4 & 2.2 & 10.3 & 2.0 & 38.8 & 31.4 & 28.0 \\
Ekim & 32.1 & 32.7 & 37.0 & 21.0 & 19.3 & 21.0 & 2.3 & 12.3 & 35.2 & 46.4 & 53.7 & 48.5 \\
Kasım & 28.5 & 21.4 & 26.9 & 16.5 & 9.4 & 14.9 & 0.0 & 62.1 & 68.4 & 34 & 53.7 & 65.5 \\
\hline
\end{tabular}

Kaynak: Șanlıurfa Meteoroloji Müdürlüğü (Anonim, 2012)

Source: Șanlıurfa Meteorology Directorate (Anonymous, 2012)

Vejetasyon süresi boyunca tekleme, el çapası, traktör çapası, yabancı ot kontrolü, hastalık ve zararlılarla mücadele yapılmıștır. Günlük buharlașma değerleri ve bitkinin intiyacı göz önünde tutularak 8-10 gün aralıklarla sulama yapılmıștır (Öktem ve ark. 2003). Silaj hasatları; koçanda süt çizgisi $2 / 3$ oranında olduğunda yapılmıștır. Dört sıradan olușan mısır parsellerindeki kenar tesirleri atıldıktan sonra parsellerdeki ortada yer alan iki sıra (1.4 $\mathrm{m} \times 5.0 \mathrm{~m}=7.0 \mathrm{~m}^{2}$ ) bıçkı yardımıyla toprak yüzeyinden kesilerek hasat edilmiș ve zaman kaybedilmeden tartımı yapılmıștır.

Her parselde tesadüfen seçilen iki bitki (bütün aksamları) kıyıldıktan sonra $70^{\circ} \mathrm{C}$ 'de 48 saat etüvde kurutulmuș ve bitki öğütme makinesinde öğütülüp $1 \mathrm{~mm}$ 'lik eleklerden geçirilmiștir. Kül miktarı için 5 g'ık, diğer kalite analizleri için $0.5 \mathrm{~g}$ 'ık numuneler alınmıștır. NDF (Nötral Deterjan lif), ADF (Asit Deterjan Lif), ADL (Asit Deterjan Lignin) ve Ham selüloz analizleri Vansoset et al. (1991) tarafından tanımlanan metoda göre Ankom Fiber Analysis cihazında yapılmıștır. Elde edilen bulgular
JUMP paket programı yardımıyla varyans analizi ve LSD testine tabi tutulmuștur.

\section{Bulgular}

Yeșil Ot Verimi ve NDF (Nötral Deterjan Lif)

\section{Değeri}

Varyans analizine göre; silaj verimi bakımından araștırmanın 2010 ve 2011 yıllarında bitki sıklıkları arasında istatistiki olarak önemli farklar tespit edilirken ( $\mathrm{P} \leq 0.01)$, 2012 yılında farklılık bulunmamıștır. Çizelge 2'de görüldüğü gibi, silaj verimi 2010 yılında 5583 kg/da (5494 bitki/da) ile 7307 kg/da (14.285 bitki/da) arasında, 2011 yılında 5415 kg/da (5494 bitki/da) ile 6873 (14.285 bitki/da) arasında değișmiștir.

Ekim sıklığı bakımından yıllar ortalamasında silaj verimi 5335 ile 6884 kg/da arasında değișmiștir. En yüksek silaj verimi 6884 kg/ da ile 10 cm'lik sıra üzerinde (14.285 bitki/da) belirlenirken, en düșük silaj verimi 5335 kg/da ile $26 \mathrm{~cm}$ sıra üzeri mesafede (5494 bitki/da) bulunmuștur. Bitki sıklığı arttıkça silaj verimi artmıștır.

Çizelge 2. 2010, 2011 ve 2012 yıllarına ait silaj verimi ve NDF (Nötral Deterjan Lif) değerleri

Table 2. Silage yield and NDF (Neutral Detergent Fiber) values for the years 2010, 2011 and 2012

\begin{tabular}{lcccccccc}
\hline \multirow{2}{*}{$\begin{array}{l}\text { Ekim sıklı̆ı } \\
\text { (bitki/da) }\end{array}$} & \multicolumn{3}{c}{ Silaj Verimi (kg/da) } & \multicolumn{4}{c}{ NDF (\%) (Nötral Deterjan Lif) } \\
\cline { 2 - 8 } 14285 & $7307 \mathrm{a \dagger}$ & $6873 \mathrm{a}$ & 6471 & $6884 \mathrm{~A}$ & $51.22 \mathrm{a}$ & $52.55 \mathrm{a}$ & $51.29 \mathrm{a}$ & 51.69 \\
10204 & $6871 \mathrm{ab}$ & $6404 \mathrm{ab}$ & 5891 & $6389 \mathrm{~B}$ & $50.98 \mathrm{ab}$ & $52.28 \mathrm{ab}$ & $51.06 \mathrm{ab}$ & 51.44 \\
7937 & $6346 \mathrm{~b}$ & $6166 \mathrm{~b}$ & 5673 & $6062 \mathrm{C}$ & $50.77 \mathrm{bc}$ & $52.06 \mathrm{a}-\mathrm{c}$ & $50.81 \mathrm{bc}$ & 51.21 \\
6493 & $5975 \mathrm{bc}$ & $5744 \mathrm{bc}$ & 5241 & $5653 \mathrm{D}$ & $50.31 \mathrm{~cd}$ & $51.88 \mathrm{bc}$ & $50.57 \mathrm{~cd}$ & 50.92 \\
5494 & $5583 \mathrm{c}$ & $5415 \mathrm{c}$ & 5007 & $5335 \mathrm{E}$ & $50.09 \mathrm{~d}$ & $51.66 \mathrm{c}$ & $50.26 \mathrm{~d}$ & 50.67 \\
Ortalama & $6416 \mathrm{~A}$ & $6120 \mathrm{~B}$ & $5657 \mathrm{C}$ & 6064 & 50.67 & 52.09 & 50.80 & 51.19 \\
CV & 6.27 & 7.33 & 2.69 & 5.84 & 0.44 & 0.48 & 0.33 & 0.42 \\
LSD & $720.53^{\star \star}$ & $865.52^{\star \star}$ & öd & $78.62^{\star \star}$ & $0.42^{\star \star}$ & $0.47^{\star \star}$ & $0.32^{\star \star}$ & öd \\
\hline
\end{tabular}

*: 0.05 seviyesinde önemli; **: 0.01 seviyesinde önemli; öd: önemli değil. YIl (LSD): $44.94^{* *}$

$\dagger$ : Aynı sütunda aynı harf grubuna giren ortalamalar arasında 0.05 seviyesinde önemli farklılık yoktur

*: Significant at 0.05 level; **: significant at 0.01 level; öd: no significant; Year (LSD): 44.94 **

$t:$ There is no significant difference among the averages entering the same letter group at 0.05 level 
Varyans analizine göre; NDF (Nötral Deterjan Lif) bakımından her üç deneme yııında da ekim sıklıkları arasında istatistiki olarak önemli farklılıklar saptanmıștır $(P \leq 0.01)$. NDF değeri 2010 yılında \%50.09 (5494 bitki/da) ile $\% 51.22$ (14.285 bitki/da) arasında, 2011 yllında \%51.66 (5494 bitki/da) ile \%52.55 (14.285 bitki/da) arasında, 2012 yilında ise \%50.26 (5494 bitki/da) ile \%51.29 (14.285 bitki/da) arasında değișmiștir. Bitki sıklığı arttıkça NDF değerinde artıș gözlenmiștir.

\section{ADF (Asit Deterjan Lif) ve ADL (Asit Deterjan Lignin) Değerleri}

ADF (Asit Deterjan Lif) bakımından 2010 yilında $(P \leq 0.01)$ ve 2011 yilinda $(P \leq 0.05)$ istatistiki olarak önemli farklılıklar belirlenirken, 2012 yılında bitki sıklıkları arasında istatistiksel olarak fark bulunmamıștır. Çizelge 3'te görüldüğü gibi ADF değeri araștırmanın 2010 yllında \%25.66 (5494 bitki/da) ile \%26.33 (14.285 bitki/da) arasında değișmiștir.

En yüksek ADF değeri 2011 yılında \%26.89 ile en yüksek bitki sıklığında (14.285 bitki/da) elde edilirken, en düșük ADF değeri \%26.51 (5494 bitki/da) ile en düșük bitki sıklı̆̆ında elde edilmiștir. ADF değeri 2012 yilında \%25.33 ile \%25.85 arasında değișmiștir. Bitki sıklığı arttıkça ADF değerinde artıș gözlenmiștir.

ADL (Asit Deterjan Lignin) bakımından 2010 yilında $(P \leq 0.01)$ ve 2011 yilında $(P \leq 0.05)$ istatistiki olarak önemli farklııklar belirlenirken, 2012 yılında bitki sıklıkları arasında istatistiksel farklılık bulunmamıștır. ADL oranları 2010 yllında; \%4.02 (5494 bitki/da) ile \%4.12 (14.285 bitki/da) arasında, 2011 yilında \%2.94
(5494 bitki/da) ile \%3.03 (14.285 bitki/da) arasında değișmiștir. ADL değeri 2012 yılında ise \%4.14 ile \%4.30 arasında değișmiștir. Bitki sıklığı arttıkça ADL değerinde artıș gözlenmiștir (Çizelge 3).

\section{Ham Selüloz Oranı ve Kül Oranı}

Ham selüloz parametresi açısından denemenin 2010 yılında bitki sıklıkları istatistiki olarak önemli bulunmazken, 2011 ve 2012 yıllarında istatistiki olarak önemli farklılık gözlenmiștir $(P \leq 0.01)$. Ham selüloz oranı 2010 yilında \%23.44 (5494 bitki/da) ile \%24.05 (14.285 bitki/da) arasında, 2011 yılında \%23.91 (5494 bitki/da) ile \%24.27 (14.285 bitki/da) arasında, 2012 yılında \%26.92 (5494 bitki/da) ile \%27.46 (14.285 bitki/da) arasında değișmiștir (Çizelge 4). Bitki sıklığı arttıkça ham selüloz değerinde artıș gözlenmiștir.

Kül oranı bakımından 2010 ( $\mathrm{P} \leq 0.01), 2011$ $(P \leq 0.05)$ ve $2012(P \leq 0.01)$ deneme yıllarında ekim sıklıkları arasında istatistiki olarak önemli farklılıklar saptanmıștır. Kül oranı 2010 yılında \%6.63 (5494 bitki/da) ile \%7.11 (14.285 bitki/ da) arasında değișmiștir. En düșük kül oranı değeri 2011 yılında \%7.46 (5494 bitki/da) ile en düșük bitki sıklığında, en yüksek kül oranı ise \%7.77 (14.285 bitki/da) ile en yüksek bitki sıklığında elde edilmiștir. Kül oranı 2012 yılında \%7.54 (5494 bitki/da) ile \%7.92 (14.285 bitki/ da) arasında değișmiștir (Çizelge 4). Bitki sıklığı arttıkça kül oranı değerinde artıș gözlenmiștir.

\section{Tartıșma ve Sonuç}

Araștırmada en yüksek silaj verimi değeri $6884 \mathrm{~kg} / \mathrm{da}$ ile $10 \mathrm{~cm}$ 'lik sıra üzerinde (14.285

Çizelge 3. 2010, 2011 ve 2012 yıllarına ait ADF (Asit Deterjan Lif) ve ADL (Asit Deterjan Lignin) değerleri Table 3. ADF (Acid Detergent Fiber) and ADL (Acid Detergent Lignin) values for the years 2010, 2011 and 2012

\begin{tabular}{lcccccccc}
\hline \multirow{2}{*}{$\begin{array}{l}\text { Ekim sıklı̆̆ } \\
\text { (bitki/da) }\end{array}$} & \multicolumn{3}{c}{ ADF (\%) (Asit Deterjan Lif) } & \multicolumn{3}{c}{ ADL (\%) (Asit Deterjan Lignin) } \\
\cline { 2 - 8 } 14285 & 2010 & 2011 & 2012 & Ortalama & 2010 & 2011 & 2012 & Ortalama \\
\hline 10204 & $26.33 \mathrm{a \dagger}$ & $26.89 \mathrm{a}$ & 25.85 & 26.36 & $4.12 \mathrm{a}$ & $3.03 \mathrm{a}$ & 4.30 & 3.81 \\
7937 & $25.99 \mathrm{bc}$ & $26.82 \mathrm{ab}$ & 25.73 & 26.25 & $4.08 \mathrm{~b}$ & $3.00 \mathrm{ab}$ & 4.26 & 3.78 \\
6493 & $25.88 \mathrm{~cd}$ & $26.60 \mathrm{bc}$ & 25.48 & 25.99 & $4.04 \mathrm{~cd}$ & $2.97 \mathrm{bc}$ & 4.18 & 3.73 \\
5494 & $25.66 \mathrm{~d}$ & $26.51 \mathrm{c}$ & 25.33 & 25.83 & $4.02 \mathrm{~d}$ & $2.94 \mathrm{c}$ & 4.14 & 3.70 \\
Ortalama & 26.01 & 26.71 & 25.59 & 26.10 & 4.06 & 2.98 & 4.22 & 3.75 \\
CV & 0.46 & 0.43 & 0.18 & 0.38 & 0.43 & 0.78 & 0.38 & 0.51 \\
LSD & $0.22^{\star \star}$ & $0.22^{*}$ & öd & öd & $0.03^{\star \star}$ & $0.04^{*}$ & öd & öd \\
\hline
\end{tabular}

*: 0.05 seviyesinde önemli; **: 0.01 seviyesinde önemli; öd: önemli değil

$\dagger$ : Aynı sütunda aynı harf grubuna giren ortalamalar arasında 0.05 seviyesinde önemli farklılık yoktur

*: Significant at 0.05 level; **: significant at 0.01 level; öd: no significant

$t:$ There is no significant difference among the averages entering the same letter group at 0.05 level 
Çizelge 4. 2010, 2011 ve 2012 yıllarına ait ham selüloz oranı ve kül oranı değerleri Table 4. Raw cellulose and ash values for the years 2010, 2011 and 2012

\begin{tabular}{|c|c|c|c|c|c|c|c|c|}
\hline \multirow{2}{*}{$\begin{array}{l}\text { Ekim sıklığı } \\
\text { (bitki/da) }\end{array}$} & \multicolumn{3}{|c|}{ Ham selüloz oranı (\%) } & \multicolumn{5}{|c|}{ Kül oranı (\%) } \\
\hline & 2010 & 2011 & 2012 & Ortalama & 2010 & 2011 & 2012 & Ortalama \\
\hline 14285 & 24.05 & 24.27 a† & $27.46 \mathrm{a}$ & 25.26 & $7.11 \mathrm{a}$ & $7.77 \mathrm{a}$ & $7.92 \mathrm{a}$ & 7.60 \\
\hline 10204 & 23.89 & $24.20 \mathrm{ab}$ & $27.36 \mathrm{a}$ & 25.15 & $6.92 \mathrm{ab}$ & $7.64 \mathrm{ab}$ & $7.86 \mathrm{ab}$ & 7.47 \\
\hline 7937 & 23.75 & $24.11 \mathrm{abc}$ & $27.14 \mathrm{~b}$ & 25.00 & $6.85 \mathrm{~b}$ & $7.59 a b$ & $7.75 \mathrm{bc}$ & 7.40 \\
\hline 6493 & 23.64 & $24.03 \mathrm{bc}$ & $26.99 \mathrm{bc}$ & 24.89 & $6.74 \mathrm{bc}$ & 7.52 b & $7.67 \mathrm{~cd}$ & 7.31 \\
\hline 5494 & 23.44 & $23.91 \mathrm{c}$ & 26.92 c & 24.76 & $6.63 \mathrm{c}$ & 7.46 b & $7.54 \mathrm{~d}$ & 7.21 \\
\hline Ortalama & 23.76 & 24.10 & 27.17 & 25.01 & 6.85 & 7.59 & 7.75 & 7.40 \\
\hline CV & 0.22 & 0.41 & 0.31 & 0.32 & 1.48 & 1.27 & 0.97 & 1.23 \\
\hline LSD & öd & $0.19^{\star *}$ & $0.15^{\star \star}$ & öd & $0.19^{\star *}$ & $0.18^{*}$ & $0.14^{\star \star}$ & öd \\
\hline
\end{tabular}

*: 0.05 seviyesinde önemli; **: 0.01 seviyesinde önemli; öd: önemli değil

†: Aynı sütunda aynı harf grubuna giren ortalamalar arasında 0.05 seviyesinde önemli farklılık yoktur

*: Significant at 0.05 level; **: significant at 0.01 level; öd: no significant

$t:$ There is no significant difference among the averages entering the same letter group at 0.05 level

bitki/da) belirlenmiștir. Araștırma bulgularımızı destekler nitelikte Saruhan ve Șireli (2005) birim alanda bitki sayısının artması ile silaj veriminin arttığını, $70 \times 10 \mathrm{~cm}$ ekim sıklığının ideal olduğunu belirtmișlerdir. Cox and Cherney (2001) bitki yoğunlukları artıkça silaj veriminin arttığını bildirmișlerdir. Bir bașka araștıııcı silaj mısırda birim alana yoğun bitki ekiminin tercih edilmesi gerektiğini belirtmektedir (Çarpıcı ve ark., 2010).

Araștırmada bitki sıklığı arttıkça silaj verimi, NDF, ADF, ADL, ham selüloz ve kül miktarları değerleri artmıș ancak silaj kalitesinde azalma gözlenmiștir. Sık ekimlerde bitki koçanlarının küçük, tane tutumunun az olması nedeniyle yem kalite değerlerinin düștüğü görülmüștür. Araștırmadan elde edilen 3 yılın ortalamasına göre; en düșük ekim sıklığından en yükseğe doğru NDF \%50.67-51.69, ADF \%25.8326.36, ADL \%3.70-3.81, ham selüloz \%24.7625.26 ve kül \%7.60-7.21 arasında değișmiștir.

Bulgularımız bitki yoğunlukları arttıkça dekara hasat edilen yeșil ot veriminin arttığını ve yem

\section{Kaynaklar}

Anonim, 2017. Șanlıurfa ilinin 2010-2012 yllı iklim verileri. Meteoroloji Müdürlüğü, Șanlıurfa

Anonim, 2017. Türkiye İstatistik Kurumu, http:// www.tuik.gov.tr (Erișim tarihi: 10.12.2016)

Baron VS., Najda HG., and Stevenson FC., 2006. Influence of population density, row spacing and hybrid on forage corn yield and nutritive value in a cool-season environment. Canadian Journal of Plant Science, 86:1131-1138

Bilgen H., Alçiçek A., Sungur N., Eichhorn H. ve Walz OP., 1996. Ege bölgesi koșullarında bazı silajlık kaba yem bitkilerinin hasat teknikleri ve yem değeri üzerine araștırmalar. Hayvancllık Kongresi, 18-20 Eylül 1996, İzmir. Cilt I, s. 781788 kalitesinin düștüğünü bildiren bazı araștıııcılar tarafından desteklenmektedir (Cox and Cherney, 2001; Baron et al., 2006; Stanton et al., 2007). Araștırma sonuçlarımızla uyumlu olarak bașka bir araștırmada; NDF, ADF, ADL, ham selüloz ve kül yüzdelik değerlerinin sırasıyla; \%45.87-60.52, \%28.18-35.76, \%2.64-4.44, \%17.69-24.76 ve \%5.18-7.82 olduğu ve sıklıklar artıkça kalite komponentleri değerlerinin arttığı bildirilmiștir (Özdüven ve ark., 2011). Bulgularımızı destekler nitelikte seyrek ekimden sık ekime doğru NDF'nin \%48.11-56.89, ADF'nin \%22.23-26.32, ADL'nin $\% 1.42-2.21$, ham selülozun \%25.44-30.35 arasında değiștiği bildirilmiștir (Radosavljevic et al., 2015).

Silajlık mısırda ideal yemlik kalite değer aralıklarının, NDF için \%35-55, ADF için \%20 -33, ADL için \%2.8-4.1, kül için \%6'dan küçük olması gerektiği belirtilmiștir (Linn et al., 2006). Araștırmadan elde edilen bulgular NDF, ADF ve $A D L$ değerlerinin belirtilen sınırlar içerisinde yer aldığını, kül oranının ise yüksek olduğunu göstermektedir.

Cox WJ., and Cherney DR., 2001. Row spacing, plant density and nitrogen effects on corn silage. Agron. J., 93: 597-602

Çarpıcı EB., Çelik N., and Bayram G., 2010. Yield and quality of forage maize as influenced by plant density and nitrogen rate. Turkish Journal of Field Crops, 15(2): 128-132

Doğan R., Turgut í. ve Yürür N., 1997. Bursa koșullarında yetiștirilen atdiși mısır (Zea mays indentata Sturt.) çeșitlerinin silajık verim ve kalitesine bitki sıklığının etkisi. Türkiye II. Tarla Bitkileri Kongresi, 22-25 Eylül, Samsun, s. 467471 
Hashemi M., Herbert SJ., and Putnam DH., 2005. Yield response of corn to crowding stress. Agron. J., 97: 839-846. doi:10.2134/agronj2003.0241

Jeschke M., and Curran B., 2010. Plant population effects on corn silage yield and quality. Crop Insights, Agron. J., 18(8): 1-4

Kim JD., Kwon CH., and Kim DA., 2001.Yield and quality of silage corn as affected by hybrid maturity, planting date and harvest stage. Asian-Aust. J. Anim. Sci., 14: 1705-1711

Linn J., Salfer J., Martens D., and Peterson P., 2006. Guide to evaluating corn silage quality. Clippings, 4: 1-2

Lorenz AJ., 2009. Characterization, inheritance, and covariation of maize. Traits Relevant to Cellulosic Biofuels Production. UMI, ProQuest LLC, Ann Arbor, MI, pp. 1 -178

Öktem A. ve Öktem AG., 2005. Farklı sıra üzeri mesafelerinin üç silajık mısır genotipinin (Zea mays L. indentata) yemlik değeri üzerine etkisi. III. Ulusal Hayvan Besleme Kongresi, 7-10 Eylül, s. 523-527, Adana

Özdüven ML., Koç F., Polat C., Coșkuntuna L., Bașkavak S. ve Șamlı SH., 2009. Bazı mısır çeșitlerinde vejetasyon döneminin silolamada fermantasyon özellikleri ve yem değeri üzerine etkileri, Tekirdağ Ziraat Fakültesi Dergisi, 6(2): 121-129
Radosavljević M., Terzić D., Semenčenko V., Milašinović-Šeremešić M., Pajić Z., Mladenović Drinić S., and Todorovi G., 2015. Comparison of selected maize hybrids for feed production. Journal on Processing and Energy in Agriculture, 19(1): 38-43

Saruhan V. ve Șireli D, 2005. Mısır (Zea mays L.) bitkisinde farklı azot dozları ve bitki sıklığının koçan, sap ve yaprak verimlerine etkisi üzerine bir araștırma. Harran Üniversitesi Ziraat Fakültesi Dergisi, 9 (2): 45-53

Stanton D., Grombacher AW., Pinnisch R., Mason H., and Spaner D., 2007. Hybrid and population density affect yield and quality of silage maize in central Alberta. Canadian Journal of Plant Science, 87: 867-871

Patricio Soto O., Ernesto Jahn B., and Susana Arredondo S., 2002. Planting density and nitrogen fertilization of hybrid corn for silage in the irrigated Central Valley. Agricultura Tecnia (Chile), 62(2): 255-265

Vansoset PJ., Robertson JB. ve Lewis BA., 1991. Method for Dietary Fiber, Neutral detergent fiber and nostarch polysaccharides in relation to animal nutrition. Journal of Dairy Science, 74: 3583-3597 